\title{
Melôkids: um recurso digital para a educação musical desenvolvido no ensino remoto
}

\author{
Melôkids: a digital resource for music education developed in remote teaching \\ Melôkids: un recurso digital para la educación musical desarrollado en aprendizaje remoto
}

\section{Resumo}

O presente estudo tem como objetivo apresentar o processo de criação, a metodologia e a avaliação de um protótipo musical denominado Melôkids. Trata-se de um recurso digital para a Educação Musical voltado aos anos iniciais do Ensino Fundamental, desenvolvido remotamente em decorrência da pandemia da Covid 19, no contexto de uma disciplina de mestrado. Para alcançar o objetivo geral, têm-se como objetivos específicos: demonstrar quais foram as estratégias utilizadas para as tomadas de decisões sobre o tipo e o público-alvo do protótipo; detalhar o processo de criação do produto contemplando a metodologia do design thinking ensinada durante a disciplina e os aspectos da interação humano-computador (IHC); e relatar as avaliações realizadas por profissionais (professores e especialistas) e usuários finais, identificando os problemas encontrados no protótipo. A pesquisa foi de natureza aplicada, seguiu uma abordagem qualitativa e utilizou-se da pesquisa-ação em seus procedimentos. Como resultados, o artigo revela estratégias operadas no ensino remoto para a produção do protótipo musical, tais como: a interdisciplinaridade dos conteúdos que envolveram o seu desenvolvimento; a integração da metodologia adotada pelos professores da disciplina (design thinking) com a metodologia utilizada pela equipe (uso de conceitos de IHC para o melhoramento da ferramenta); a utilização da linguagem Scratch para a programação de recursos digitais; as plataformas e os recursos digitais encontrados para a adequação das atividades no formato remoto (Google Meet, SOLAR, WhatsApp, Trello e Sebrae Canvas); e por fim, os procedimentos utilizados para a avaliação do protótipo, os quais identificaram a necessidade de implementação de melhorias na ferramenta.

Palavras-chave: Música; Sistemas interativos; Interdisciplinaridade; Metodologias ágeis; Usabilidade.

\begin{abstract}
This study aims to present the creation process, methodology, and evaluation of a musical prototype called Melôkids. It is a digital resource for Music Education aimed at the early years of Elementary School, remotely developed as a result of the Covid 19 pandemic, in the context of a Master's course. To achieve the general objective, the following specific objectives are: to demonstrate which strategies were used to make decisions about the prototype's type and target audience; detail the product creation process, according to the design thinking methodology taught during the course and aspects of human-computer interaction (HCI); and report the evaluations carried out by professionals (teachers and specialists) and end-users, identifying the problems found in the prototype. The research was applied in nature, followed by a qualitative approach, and used action research in its procedures. As a result, the article reveals strategies operated in remote teaching for the production of musical prototypes, such as: the interdisciplinary content that involved its development; the Integration of the Methodology Adopted by the Teachers of the Discipline (Design Thinking) with the Methodology Used by the Team (Use of HCI Concepts to Improve the Tool); the use of the Scratch language for programming digital resources; the platforms and digital resources found to adapt activities in the remote format (Google Meet, SOLAR, WhatsApp, Trello, and Sebrae Canvas); and finally, the procedures used to evaluate the prototype, which identified the need to implement improvements in the tool.
\end{abstract}

Keywords: Music; Interactive systems; Interdisciplinarity; Agile methodologies; Usability.

\section{Resumen}

El presente estudio pretende presentar el proceso de creación, la metodología y la evaluación de un prototipo musical denominado Melôkids. Se trata de un recurso digital para la Educación Musical dirigido a los primeros años de la Escuela Primaria, desarrollado a distancia a raíz de la pandemia de Covid 19, en el contexto de una disciplina de maestría. Para lograr el objetivo general, los objetivos específicos son: demostrar cuáles fueron las estrategias utilizadas para la toma de decisiones sobre el tipo y el público objetivo del prototipo; detallar el proceso de creación 
del producto contemplando la metodología de design thinking enseñada durante la disciplina y los aspectos de la interacción persona-ordenador (HCI); y reportar las evaluaciones realizadas por profesionales (profesores y expertos) y usuarios finales, identificando los problemas encontrados en el prototipo. La investigación fue de carácter aplicado, siguió un enfoque cualitativo y utilizó la investigación-acción en sus procedimientos. Como resultados, el artículo revela estrategias operadas en la enseñanza a distancia para la producción del prototipo musical, tales como: la interdisciplinariedad de los contenidos que implicaron su desarrollo; la integración de la metodología adoptada por los profesores de la disciplina (design thinking) con la metodología utilizada por el equipo (uso de conceptos de HCI para la mejora de la herramienta); el uso del lenguaje Scratch para la programación de los recursos digitales; las plataformas y recursos digitales encontrados para la adecuación de las actividades en el formato remoto (Google Meet, SOLAR, WhatsApp, Trello y Sebrae Canvas); y finalmente, los procedimientos utilizados para la evaluación del prototipo, que identificaron la necesidad de implementar mejoras en la herramienta.

Palabras clave: Música; Sistemas interactivos; Interdisciplinariedad; Metodologías ágiles; Usabilidad.

\section{Introduçãa}

Na contemporaneidade, o ensino de música na escola mediado pela utilização de tecnologias digitais da informação e da comunicação (TDIC) proporciona a promoção, a ampliação e a produção dos conhecimentos musicais no processo de ensino e aprendizagem. Recursos digitais, como jogos e simuladores digitais, são sistemas interativos que efetivam esse aprendizado. Assim, Cota (2016) ressalta que os sistemas interativos musicais cumprem as mais diversas funções, como as de ferramentas para musicalização, jogos musicais, mecanismos úteis para músicos profissionais e instrumentos virtuais.

A escola tem o papel fundamental para que ocorram tanto o desenvolvimento de habilidades próprias dos estudantes quanto a transmissão dos valores culturais e sociais por meio da música; e o professor é o sujeito capaz de nortear caminhos usando ferramentas tecnológicas, potencializando as aptidões existentes nos grupos sociais a fim de obter os melhores êxitos. De acordo com a Base Nacional Comum Curricular [BNCC] (2017), os alunos precisam perceber e explorar os elementos constitutivos da música (altura, intensidade, timbre, melodia, ritmo etc.) a partir de jogos, brincadeiras, canções e práticas diversas de composição/criação, execução e apreciação musical.

Considerando o contexto acima apresentado, foi desenvolvido como produto da disciplina de Desenvolvimento de Tecnologias Aplicadas à Educação, ministrada remotamente no Mestrado Profissional em Tecnologia Educacional da Universidade Federal do Ceará (UFC), durante o primeiro semestre de 2021, um protótipo musical que surgiu como alternativa às atividades elaboradas pelos professores em sala de aula. Vale ressaltar que, de acordo com Winckler, et al. (2000), um protótipo é uma versão simplificada de todo o projeto que se deseja construir, sendo utilizado para experimentar e para avaliar soluções.

Torna-se relevante frisar que, diante da pandemia da Covid 19, as instituições acadêmicas precisaram se organizar e encontrar estratégias para migrar suas atividades presenciais para o ensino remoto. No tocante à disciplina mencionada, não foi diferente, pois a escolha de plataformas para webconferência e de outros recursos tecnológicos teve que ser realizada. Na ótica de Rodrigues (2020), o ensino remoto é uma adaptação provisória de aulas presenciais para aulas on-line e mediadas por tecnologias digitais. Em decorrência das informações apresentadas, é crível questionar: quais as estratégias utilizadas no ensino remoto para a concepção e a avaliação de um recurso digital voltado para a Educação Musical?

Seguindo esse viés, o presente trabalho tem como objetivo geral apresentar o processo de criação, a metodologia e a avaliação de um protótipo musical denominado Melôkids. Trata-se de um recurso digital para a Educação Musical voltado aos anos iniciais do Ensino Fundamental, desenvolvido remotamente em decorrência da pandemia da Covid 19, no contexto de uma disciplina de mestrado. Já como objetivos específicos, têm-se: demonstrar quais foram as estratégias utilizadas para as tomadas de decisões sobre o tipo e o público-alvo do protótipo; detalhar o processo de criação do produto contemplando a metodologia do design thinking ensinada durante a disciplina e os aspectos da interação humano-computador (IHC); e relatar 
as avaliações realizadas por profissionais (professores e especialistas) e usuários finais, identificando os problemas encontrados no protótipo.

Em virtude do caráter interdisciplinar do recurso digital, emergiram reflexões sobre as áreas de Informática e Educação Musical, tendo como suporte os conceitos da Educação Musical, IHC e Engenharia de Software: PBL e Design Thinking. Cada um desses campos tem sua contribuição para a concepção do presente trabalho e será apresentado a seguir.

O artigo está organizado de acordo com a sequência: na Seção 2, o desenvolvimento de sistemas interativos para Educação Musical: conceitos; na Seção 3, a metodologia empregada; na Seção 4, apresentação dos resultados e discussões sobre o processo de planejamento, de concepção e de análise do Melôkids e, por fim, a Seção 5 contendo as considerações finais.

\section{Desenvolvimento de Sistemas Interativos para a Educação Musical}

O desenvolvimento de sistemas interativos musicais deve atuar como uma tarefa interdisciplinar e ser realizado coletivamente por especialistas nas áreas de Música, Educação e Ciência da Computação. Contudo, de acordo com Cheng \& Leong (2017), raramente, os cientistas da computação consultam músicos e professores de música durante a concepção de recursos digitais no processo de avaliação.

É essencial reforçar que a atenção cuidadosa para as necessidades dos usuários no decorrer da concepção de recursos digitais torna-se vital para garantir a qualidade e a aprendizagem na sala de aula. Dessa forma, deve-se perceber em tais recursos não somente os aspectos técnicos e pedagógicos, mas também os fatores relacionados à usabilidade. Consoante, Rocha \& Barros (2021) consideram a usabilidade como a simplicidade que o usuário possui ao se relacionar com um ambiente informacional digital.

Ademais, Pereira, et al. (2021), ao relatarem as perspectivas de diversos autores sobre o desenvolvimento de sistemas interativos infantis ressaltam que, ao arquitetar uma interface, o design precisa ser fácil, visando proporcionar significados e estímulos para a criança. Quando um sistema interativo a ser desenvolvido está situado na área musical, considera-se usar os recursos de multimídia. Conforme Ago (2010), entende-se por multimídia a combinação de diversos tipos de mídia, como textos, imagens estáticas, áudios, imagens em movimento e vídeos. Tais ferramentas poderão ser manuseados em uma única aplicação de computador, pois será feita a comunicação por meio de recursos sonoros, assim como visuais.

\subsection{Educação musical}

O processo de ensino de música no Brasil, ao longo do tempo, oscilou entre momentos de desvalorização e de reconhecimento, haja vista que a sua denominação já foi variada entre conteúdo e disciplina, respectivamente. Recentemente, foi identificado como uma unidade temática do componente curricular de Artes, conforme a ótica da Base Nacional Comum Curricular.

Todavia, o ensino da linguagem musical nos anos iniciais do ensino fundamental na Educação Básica do Brasil tem um papel crucial, isso porque, caso seja estimulado desde cedo, haverá potencial para contribuir em vários aspectos das etapas do desenvolvimento humano. A BNCC considera que a música pode gerar experiências de aprendizagens amplas e complexas por meio de temas, de assuntos ou de habilidades afins de diferentes componentes que podem reunir projetos, nos quais os saberes possam obter a integração de forma interdisciplinar, inclusive com o uso de diferentes recursos digitais (BNCC, 2017).

Para o educador musical, as facilidades geradas pelas TDIC resultam em novas atividades que podem ser direcionadas a estudantes em seu processo de alfabetização musical. Essas ferramentas são muito úteis para o professor, o qual poderá utilizá-las para preparar suas aulas e para realizar atividades com seus alunos. No entanto, é necessário que ele se aproprie dos 
conhecimentos prévios das características e possibilidades de aplicação para o contexto imaginado. Segundo Ago (2011), a utilização de ferramentas tecnológicas assume o papel de facilitadora, nunca ocupando o lugar do educador no processo de ensino e aprendizagem musical.

No que tange aos conteúdos que devem ser estudados para compreender a linguagem musical, ressaltam-se neste trabalho a percepção auditiva e a memória musical. Os Parâmetros Curriculares Nacionais [PCN] (1997) para o ensino fundamental destacam a importância de desenvolver a percepção auditiva e a percepção musical, criando, interpretando e apreciando músicas em um ou mais sistemas musicais.

\subsection{Interação humano-computador}

Outro conceito salutar e utilizado neste trabalho é o de IHC que, conforme Barbosa \& Silva (2010), concerne a uma área que considera a qualidade de uso de sistemas interativos e a sua implicação na vida de usuários. De modo geral, pode-se dizer que a IHC se interessa em pesquisar o design, a elaboração e a avaliação de sistemas interativos com vistas à produção de interfaces de alta qualidade.

A IHC possui modelos de processo, de métodos e de técnicas para o desenvolvimento de sistemas interativos focados nos aspectos relacionados com a interação entre homem e máquina. De acordo com Barbosa \& Silva (2010), a IHC possui uma abordagem caracterizada pela iniciação de projeto de um sistema interativo, investigando sujeitos envolvidos e, ainda, preferências, propósitos, tarefas, obrigações, estímulos, dispositivos utilizados, domínios, contextos de uso interligados a eles.

Para que um sistema interativo possa dispor de uma qualidade em IHC, é necessário que esse dispositivo apresente características enfáticas, sendo elas: usabilidade, experiência com o usuário, acessibilidade e comunicabilidade, tanto na interação quanto na interface. Conforme Barbosa \& Silva (2010), a interface é o único meio de contato entre o usuário e o sistema. Nesse viés. em um mercado cada vez mais competitivo, são fatores de destaque em um produto: uma interface de fácil utilização, de manutenção, de confiança e de satisfação quanto ao prazo de entrega e ao custo para o usuário.

Para identificar as reais necessidades dos usuários, pode ser utilizado o modelo simples como um dos processos propostos pela IHC. De acordo com Barbosa \& Silva (2010), esse processo de design de IHC ressalta a importância do design centrado no usuário (Ver Figura 1).

Figura 1. Modelo simples de processo de design de IHC.

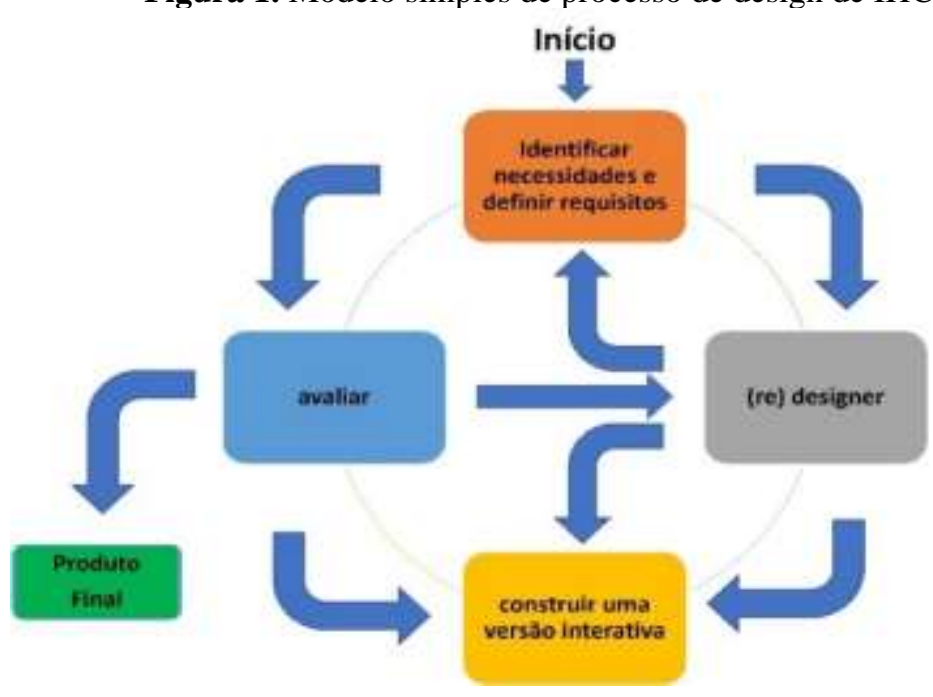

Fonte: Barbosa \& Silva. Processo simples de IHC, 2010, p. 102. 
Nesse viés, de acordo com Sharp, et al. (2007), os passos do processo se caracterizam pela identificação das necessidades dos usuários e pela definição dos requisitos, pela busca por designer adequado e pela construção de versões interativas facilitando a avaliação de IHC. Destaca-se que, no processo, a iteração entre as atividades ocorre quantas vezes forem necessárias, sendo limitada apenas pelo orçamento, tempo e recursos disponíveis. No que tange à avaliação, Barbosa \& Silva (2010) ressaltam que o processo de design acontece a partir do momento em que há uma avaliação e depois dela ocorre a conclusão de que a solução de IHC atende às necessidades e aos requisitos identificados.

Para avaliação dos sistemas interativos referentes à IHC, são propostos vários tipos de métodos que podem ser classificados por inspeção e por observação. A avaliação heurística é um tipo de método de inspeção que, de acordo com Nielsen (1990), foi criado para que, durante o processo de designer iterativo, problemas de usabilidade pudessem ser encontrados. Para Barbosa \& Silva (2010), esse método possui um conjunto de diretrizes de usabilidade, que são conhecidas por heurísticas de Nielsen, as quais descrevem as características desejáveis da interação e da interface de um sistema interativo.

\subsection{Engenharia de software: PBL e Design Thinking}

As diversas áreas do conhecimento possuem perspectivas distintas sobre a concepção de sistemas interativos, apresentando critérios particulares de qualidade e com graus diferentes de importância. A Engenharia de Software é um campo focado no desenvolvimento de sistemas interativos de forma sistemática, definindo modelos de processos, métodos e técnicas. Desse modo, na concepção de Barbosa \& Silva (2010), ela está interessada na construção de sistemas interativos mais eficientes, robustos, livres de erros, e que disponham de fácil manutenção.

Tal disciplina é uma subárea da computação e que, no cenário atual, o surgimento de novas metodologias de ensino desperta grande interesse no ambiente educacional, tendo em vista que visa à preparação dos estudantes das universidades, gerando novas habilidades nos aspectos técnicos e não técnicos relacionados ao desenvolvimento de programas. O intuito dessas metodologias, conforme Meireles \& Bonifácio (2015), é fornecer a flexibilidade, melhorar a integração e incentivar as práticas de aprendizagem a partir de uma perspectiva pedagógica inovadora.

Importante salientar que grande parte das instituições tem adotado estratégias diferentes, por meio de abordagem de Aprendizagem Baseada em Problemas (PBL), do inglês Problem-Based Learning. Para Meireles \& Bonifácio (2015), a associação de PBL e de métodos ágeis possibilita a criação de um ambiente mais dinâmico, suscitando interesse e motivação por parte dos alunos.

Nesse viés, destaca-se o design thinking como uma das metodologias que podem ser aplicadas em diversas áreas do conhecimento para o desenvolvimento de sistemas interativos que atendam as reais necessidades das pessoas que o utilizam. De acordo com Coutinho, et al. (2016), o design thinking é uma ação direcionada à pessoa, e essa atitude estimula a inovação e a solução de problemas complexos conforme a Figura 2.

Figura 2. Processo de design thinking.

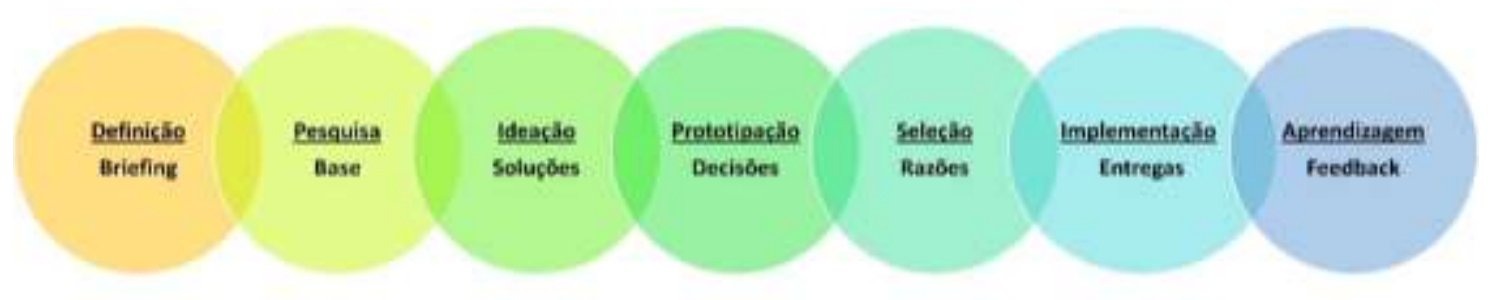

Fonte: Coutinho et al. Adaptação do processo de design thinking, 2016. 
Os autores definem que o processo dessa abordagem tem por base a definição do problema na pesquisa que envolve o problema e os usuários finais, na prototipação para exploração das ideias, na seleção em que há as soluções revisadas, na implementação que comporta o desenvolvimento do projeto e a entrega do produto para o cliente e, por fim, na aprendizagem que auxilia os projetistas a melhorarem seu desempenho.

\section{Metodologia}

A proposta deste trabalho visou apresentar o processo de criação, a metodologia e a avaliação de um protótipo musical denominado Melôkids. A pesquisa de natureza aplicada teve uma abordagem qualitativa, pressupondo a compreensão dos diferentes fenômenos presentes na realidade estudada, ainda que em alguns aspectos variáveis e dados de natureza quantitativa tenham sido utilizados e coletados para o levantamento de requisitos e a avaliação do Melôkids. Barbosa \& Silva (2010) afirmam que a pesquisa qualitativa consiste em um conjunto de práticas interpretativas e materiais que tornam o mundo visível e o transformam em uma série de representações, incluindo anotações em campo, entrevistas, conversas, fotografias, gravações e anotações pessoais.

No que tange aos procedimentos, utilizou-se a pesquisa-ação caracterizada pela interação entre sujeitos e pesquisadores na produção de novos conhecimentos. De acordo com Franco (2005), na pesquisa-ação o pesquisador assume dois papéis: o de pesquisador e o de participante do grupo.

\subsection{Materiais utilizados e instrumentos de coletas de dados}

Nesta seção, destacam-se os materiais utilizados para a realização das aulas da disciplina e para as reuniões dos integrantes da equipe do Melôkids. O aplicativo WhatsApp foi utilizado para as interações assíncronas por meio de troca de mensagens e comunicação em áudio e vídeo e as plataformas de webconferência SOLAR e Google Meet, foram utilizadas para promover as interações síncronas entre professores e estudantes. Para David, et al. (2020), o SOLAR é um ambiente virtual de aprendizagem desenvolvido para oferta de cursos na modalidade a distância pela Universidade Federal do Ceará.

A linguagem de programação escolhida para o desenvolvimento da versão interativa do protótipo foi o Scratch, pois apresenta uma linguagem de programação visual e simplificada que é utilizada em sistemas operacionais como Windows e Linux, tornando possível criar jogos, histórias e animações com scripts feitos com blocos. Sobreira et al. (2013) reforçam e afirmam que o Scratch possibilita a criação de jogos, animações, histórias animadas, entres outros recursos, por meio de blocos de encaixe intuitivo.

Nessa perspectiva, o melôkids foi inicialmente desenvolvido no Scratch, considerando a importância do desenvolvimento de um protótipo interativo, uma vez que, conforme Barbosa \& Silva (2010), a representação de uma alternativa de solução tem um papel de manifestar a proposta de um design para o cliente, o usuário e o desenvolvedor, que por sua vez, estes podem compreender e opinar sobre o projeto do sistema, antes mesmo de ele ser construído e inserido no cotidiano das pessoas.

Os instrumentos de coletas de dados utilizados foram: questionários eletrônicos semiestruturados, diários de campos e recursos audiovisuais e fotográficos.

\subsection{Procedimentos metodológicos}

O protótipo Melôkids é um produto da disciplina de Desenvolvimento de Tecnologias aplicadas à Educação, ministrada no Mestrado Profissional em Tecnologia Educacional da Universidade Federal do Ceará (UFC), realizada no 
primeiro semestre de 2021. A disciplina ocorreu por meio da plataforma digital SOLAR, e sua proposta baseou-se em uma metodologia aplicando conceitos de Engenharia de Software com as ideias de design thinking.

Os estudantes que cursaram a disciplina foram divididos em equipes que variavam entre quatro e cinco integrantes cada, viabilizando o desenvolvimento de sistemas interativos, tais como: sistemas web, dispositivos móveis, jogos digitais e animações gráficas, que deveriam ser entregues como produto no final do semestre. Dessa maneira, a equipe da qual a autora do presente trabalho é uma das integrantes, recorreu ao desenvolvimento de um recurso digital que agregou aspectos de jogos e simuladores digitais como um instrumento facilitador no processo de ensino e aprendizagem musical.

A equipe foi composta de estudantes formados em: Música, Artes, Pedagogia e Química. Esse ambiente heterogêneo de profissionais com diferentes formações facilitou o surgimento de ideias, de criatividade e de inovação. Ademais, para Barbosa \& Silva (2010), essa multidisciplinaridade auxilia a análise do problema e de alternativas de soluções sob pontos de vista bem variados, enriquecendo, assim, o resultado do trabalho.

Após a definição do problema e a escolha do tipo de recurso que seria desenvolvido pela equipe, as etapas para a produção do protótipo solicitado pelos professores da disciplina foram: 1) a criação do Business Model Canvas (BMC), um modelo de negócio que ilustra os segmentos mais importantes de um negócio (proposta de valor, relacionamento com o cliente, canais, segmentos de mercado, atividades chave, recursos chave, parceiros chave, estruturas de custos e fontes de renda); 2) o planejamento das etapas de desenvolvimento do projeto mediante a plataforma Trello, contendo colunas como: backlog, gerenciamento, protótipo 1, protótipo 2 e protótipo final, com a descrição das necessidades do usuário do produto (User Story) e 3) a apresentação de três entregas do protótipo para os professores e demais alunos da turma.

Como estratégia para o desenvolvimento do recurso digital com qualidade, a equipe utilizou não apenas a proposta metodológica implementada pelos professores na disciplina (Design Thinking), mas também do modelo simples de processo de design de IHC e das heurísticas de Nielsen para avaliação do protótipo, conforme serão detalhados nas etapas a seguir. De acordo com Silva et al. (2004), é possível desenvolver sistemas interativos considerando os aspectos relevantes da Engenharia de Software em conjunto com aqueles considerados pela IHC.

\section{Resultados e Discussão}

Para atingir o primeiro passo do método Design Thinking que está relacionado a identificação de um problema e o público-alvo, os estudantes utilizaram uma ferramenta de gerenciamento estratégico, o modelo de negócio Business Model Canvas (BMC). Esta ferramenta geralmente é apresentada mediante um quadro físico com a utilização de post-it e permite desenvolver e esboçar modelos de negócios novos ou existentes em uma única página. Contudo, para a realização dessa atividade de forma remota, a equipe reuniu-se, por meio da plataforma digital Google Meet, para tomadas de decisões, sugestões de ideias e preenchimento do modelo de negócio com auxílio da plataforma web Sebrae Canvas conforme a Figura 3. 
Figura 3. Modelo de negócio $B M C$.

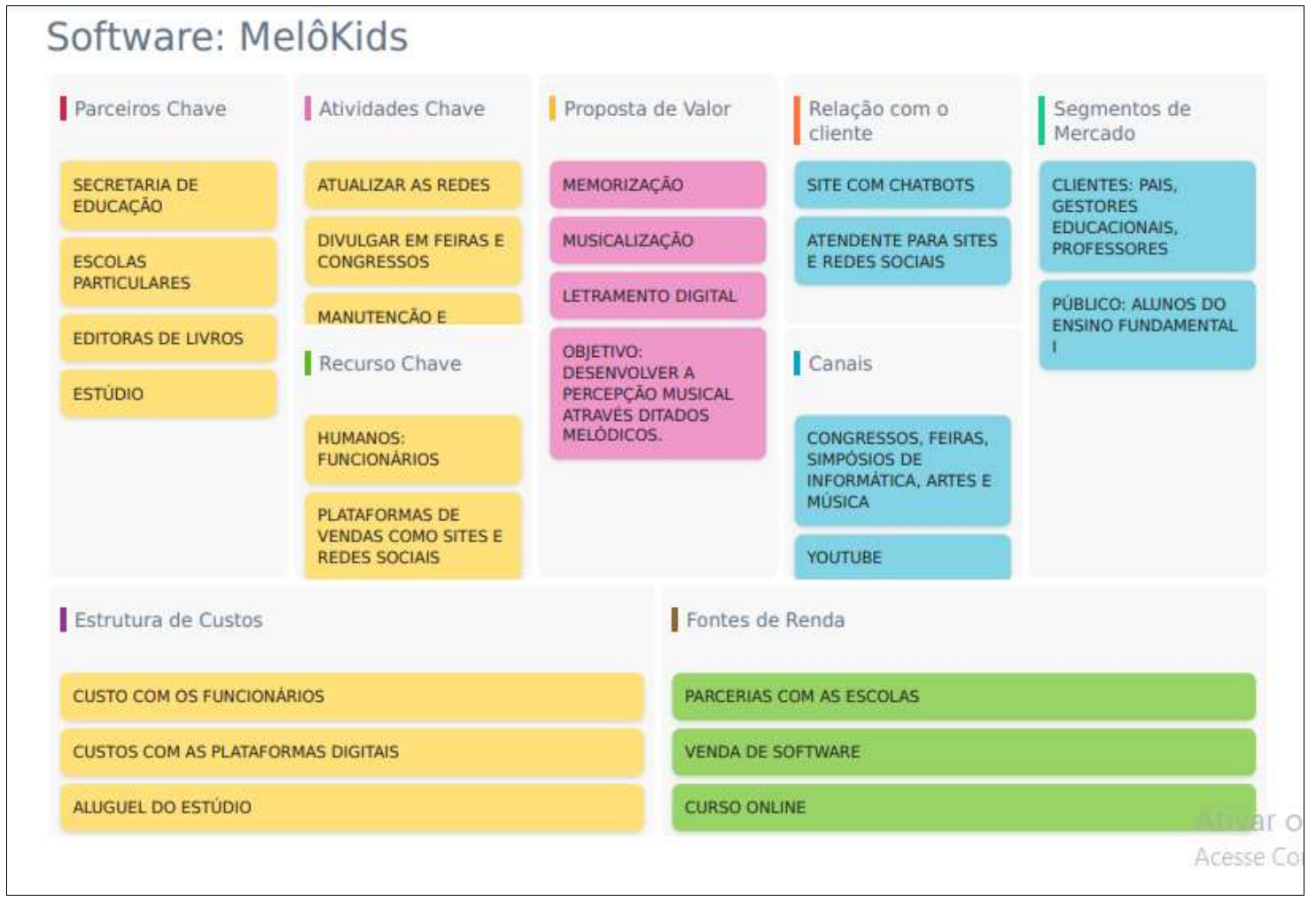

Fonte: print retirado do site Sebrae Canvas.

No encontro da equipe, algumas questões foram levantadas, tais como: Qual sistema interativo será criado? Baseado em qual problemática? Que conteúdo será abordado no recurso digital? Quem será o público-alvo? Como as atividades serão desenvolvidas? Quais as responsabilidades de cada componente da equipe?

A construção desse modelo, mediante a plataforma on-line, serviu como experimento para que fosse democratizada a compreensão dos protocolos iniciais no desenvolvimento de um sistema interativo como uma proposta de negócio. Nesse contexto, a equipe decidiu como proposta de valor que iria desenvolver um recurso digital que envolvesse a musicalização e a memorização, contemplando habilidades definidas na BNCC, cujo objetivo principal era desenvolver a percepção auditiva por meio de ditados melódicos das notas musicais.

Já nos segmentos de mercado, foram descritos como clientes: pais, gestores educacionais e professores; e os usuários finais: os alunos dos anos iniciais do Ensino Fundamental. Por anos iniciais, entende-se que é o público-alvo formado por crianças na idade escolar do $1^{\circ}$ ao $5^{\circ}$ ano. Corroborando, segundo Gordon (2000), uma criança nasce com um determinado nível de aptidão musical e este muda de acordo com a qualidade do seu ambiente musical, formal e informal, até a criança atingir os nove anos de idade. Verifica-se, na afirmação do autor, a relevância de ensinar os conceitos musicais nos primeiros anos de vida da criança, justificando, assim, a escolha e a definição do tema do sistema interativo selecionado pela equipe.

Diante do exposto, o recurso digital Melôkids desponta como uma alternativa para apoiar o ensino e a aprendizagem de música nos anos iniciais do Ensino Fundamental, estimulando a percepção auditiva musical das crianças a partir da memorização dos sons de oito notas musicais e da musicalização de canções brasileiras com registros musicais não convencionais, sendo detalhados a seguir. 


\subsection{Pesquisa: necessidades dos usuários}

Tanto o método do design thinking como a área IHC, estão interessados na construção de sistemas interativos que atendam às necessidades dos usuários, nesse viés, para a criação do recurso digital, foram utilizadas pesquisas sobre: os softwares desenvolvidos para Educação Musical; as competências e habilidades da linguagem musical na BNCC; e as visões dos usuários finais sobre o ensino de música com uso de tecnologias na escola mediante aplicação de um questionário on-line semiestruturado.

Como trabalhos relacionados, destacam-se os estudos de Jesus et al. (2008), que tratam da concepção do Zorelha, um objeto de aprendizagem disponível em sistema web, o qual propicia a aprendizagem a partir da exploração sonoro-musical e os de Ago (2011), que trazem a proposta do software Musicando como alternativa para o processo de ensino e aprendizagem de música.

Já a Base Nacional Comum Curricular (BNCC) define um conjunto de aprendizagens essenciais que todos os alunos devem desenvolver ao longo da Educação, e nela podem ser encontradas competências e habilidades necessárias ao aprendizado da linguagem musical (BNCC, 2017). Algumas delas, detalhadas no Componente Curricular de Artes, foram analisadas e serviram de base teórica para o desenvolvimento do protótipo, como:

"Perceber e explorar os elementos constitutivos da música (altura, timbre, melodia, ritmo etc.); explorar fontes sonoras diversas, em objetos do cotidiano, reconhecendo os elementos constitutivos da música e instrumentos musicais variados; explorar diferentes formas de registro musical convencional ou não convencional; experimentar improvisações, por meio de sons, dentre outros" (BNCC, 2017, p.201).

É interessante salientar que, para obter os requisitos da ferramenta digital e as suas funcionalidades, também precisa que se conheça um pouco mais a respeito do contexto sobre o qual ela será utilizada, bem como estar ciente de quem são os seus usuários, dentre outros. De acordo com Barbosa \& Silva (2010), nos processos de design de IHC, apontam-se a importância de envolver os usuários durante suas atividades para dar-lhes oportunidade de participar, direta ou indiretamente, nas decisões tomadas.

Nesse sentido, buscando envolver alunos de forma indireta nas tomadas de decisões sobre a construção do recurso digital, selecionou-se uma escola pública do Município de Maracanaú-Ceará para a aplicação de um questionário on-line semiestruturado com o intuito de colher suas visões sobre o ensino de música mediado por tecnologias na escola. A escolha da escola deve-se ao fato de alunos do $3^{\circ}$ ao $5^{\circ}$ ano do Ensino Fundamental participarem de um projeto denominado "Música e Tecnologia na Escola”, cujo projeto envolve aulas de músicas mediadas por TDIC no laboratório de informática. Ainda é somável que, no período pandêmico, as aulas aconteceram remotamente por meio do uso de aplicativos.

O link do questionário foi disponibilizado nos grupos de WhatsApp criados pela escola para aulas remotas no contexto da pandemia da Covid-19 e ficou disponível para preenchimento on-line, de 30/06/2021 a 02/07/2021. No total, 79 alunos responderam à pesquisa; $22,8 \%$ são alunos do $1^{\circ}$ ano; $22,8 \%$ do $2^{\circ}$ ano; $8,9 \%$ do $3^{\circ}$ ano; $20,3 \%$ do $4^{\circ}$ ano e $25,3 \%$ do $5^{\circ}$ ano. Com relação ao sexo, 53,2\% são estudantes do sexo feminino e 46,8\% são estudantes do sexo masculino, e a maioria estuda na escola há mais de 2 anos. No que tange às TDIC, no total de pesquisados, 96,2\% dos estudantes confirmaram possuir internet em suas residências, e a maioria utilizam o celular como ferramenta para assistir às aulas remotas.

Quando questionados sobre a importância do aprendizado de música na escola, 98,7\% dos alunos disseram que achavam relevante e detalharam explanando suas opiniões sobre o ensino de música, tais como: “divertido”, "legal”, “capaz de desenvolver habilidades", “uma terapia”, “importante para aprender um instrumento", “abre oportunidades”, “traz alegria”, “conhece as notas musicais", “aprende a tocar música”, “aprende a cantar", “estimula o aprendizado", “descobre talentos", “importante para desenvolver o gosto pela arte", dentre outras. 
Ao serem questionados se já tinham utilizados algum recurso digital para aprender música, 50\% dos alunos responderam que nunca aprenderam música utilizando recursos tecnológicos, já a outra metade respondeu que aprendeu por meio de recursos como YouTube, App Piano, Google, Snaptube, Simply Piano, Perfect Piano e outros. Por fim, na última pergunta, ao serem questionados sobre qual recurso digital gostariam de aprender os sons das notas musicais, 62,5\% dos estudantes responderam por meio "um simulador de instrumento virtual" e 37,5\% responderam mediante "um jogo".

Essa visão dos usuários finais foi de extrema relevância, tendo em vista, que a pretensão inicial da equipe era de desenvolver apenas um jogo, contudo a maioria dos alunos consideraram uma aprendizagem baseada em instrumentos virtuais. Consoante Coutinho et al. (2016) no design thinking, a etapa da pesquisa identifica os possíveis obstáculos.

De posse do resultado das pesquisas sobre softwares musicais, do conhecimento das competências e das habilidades da BNCC específicas da linguagem musical e da visão dos usuários finais sobre o ensino de música com tecnologias digitais na escola, a ideação do protótipo será detalhada a seguir.

\subsection{Requisitos}

Inicialmente, o protótipo foi concebido para ser utilizado nos sistemas operacionais Windows ou Linux, pois estes se adequam a tecnologias como computadores e notebooks. A escolha deve-se ao fato de o protótipo utilizar a integração do software com o hardware, utilizando o manuseio do teclado do computador para a interação do usuário com a interface. Contudo, as possibilidades poderão ser ampliadas para dispositivos móveis, de modo a atender as necessidades dos usuários, tendo em vista que, em sua maioria, possuem celulares como ferramentas de uso principal.

O Melôkids dispõe de um menu inicial composto por três botões, cujo acionamento deverá dar acesso aos três módulos: instruções, tocar e jogar. O módulo "instruções”, como o próprio nome descreve, está relacionado com as instruções do jogo. Já no módulo “jogar”, o usuário irá perceber, memorizar e interagir com os sons das notas musicais mediante as teclas numéricas do computador. Finalmente, no módulo “tocar”, o usuário poderá manusear um piano musical representado por uma oitava, na qual a criança utilizará o teclado numérico do computador para tocar canções.

Como técnica de modelagem para especificação dos requisitos do sistema, utilizou-se o modelo de casos de uso. Os casos de uso (Use Cases-Ucs) descrevem as capacidades ou formas de utilização do software do ponto de vista do usuário. De acordo com Yue et al. (2009), eles são utilizados para especificar o comportamento externo do sistema. Para o compartilhamento dessas informações, a ferramenta Trello foi fundamental, uma vez que permitiu aos professores e aos demais alunos da disciplina o conhecimento sobre os requisitos necessários para a construção do Melôkids do ponto de vista do aluno, conforme a Figura 4. Ademais, este instrumento, disposto na web, possui um conjunto de funcionalidades que possibilitou o controle e a atualização semanal das tarefas desenvolvidas pela equipe de forma remota. 
Figura 4. Ferramenta Trello utilizada para detalhar Use Cases.

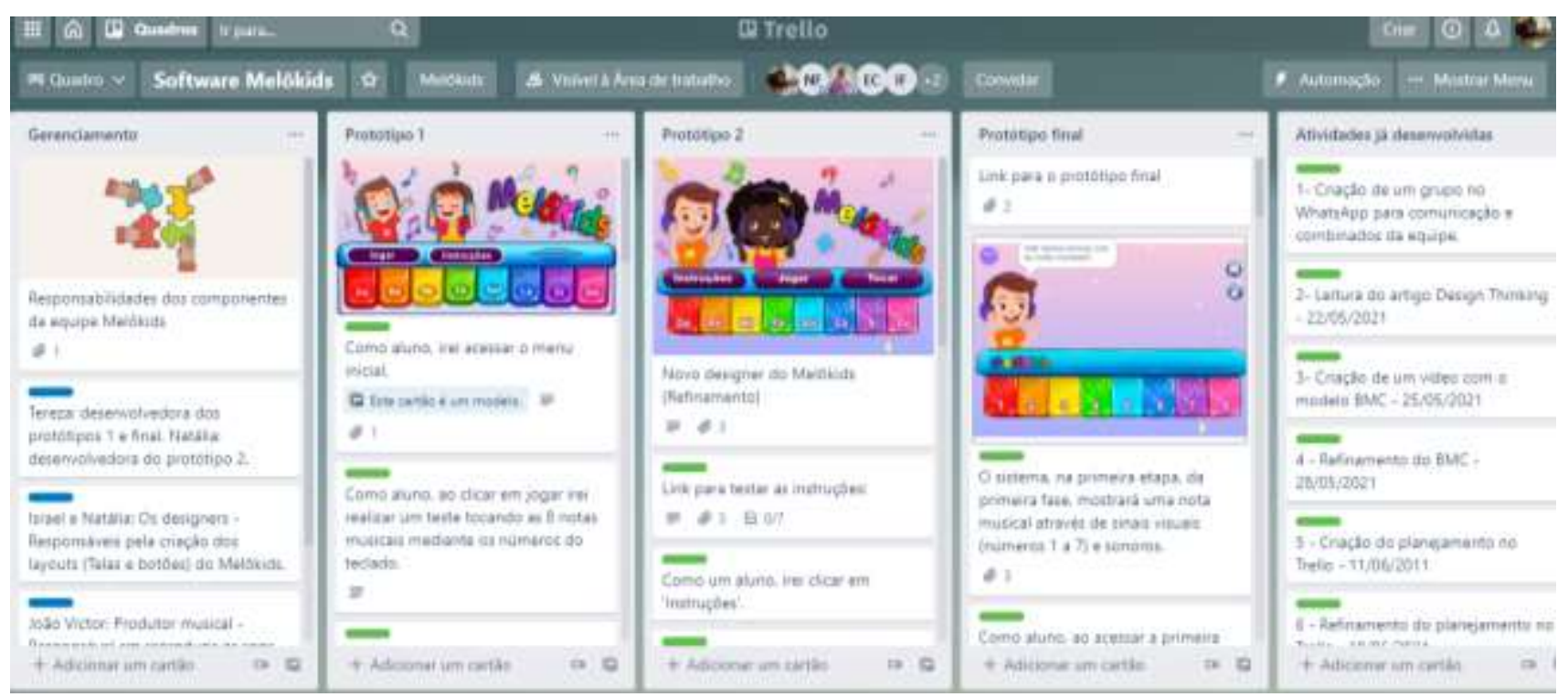

Fonte: print realizado a partir do site Sebrae Canvas.

Dessa forma, seguem no Quadro 1 os requisitos específicos para cada módulo.

Quadro 1: Requisitos dos módulos do Melôkids.

\begin{tabular}{|c|c|c|}
\hline Instruções & Jogar & Tocar \\
\hline $\begin{array}{l}\text { Ao clicar com o mouse sobre o } \\
\text { botão instruções, aparecerá um } \\
\text { cenário contendo o primeiro } \\
\text { diálogo. }\end{array}$ & $\begin{array}{l}\text { Ao acessar clicando com o } \\
\text { mouse no botão jogar, aparecerá } \\
\text { a primeira fase do jogo. }\end{array}$ & $\begin{array}{l}\text { Ao acessar clicando com o mouse no botão } \\
\text { tocar, aparecerá uma tela com um piano } \\
\text { musical composto de uma oitava. }\end{array}$ \\
\hline $\begin{array}{l}\text { Iniciará as instruções sobre o } \\
\text { módulo jogar mediante o diálogo } \\
\text { de personagens com balões de } \\
\text { falas. }\end{array}$ & $\begin{array}{l}\text { Cada fase possui duas etapas: na } \\
\text { primeira o próprio sistema } \\
\text { emitirá o som de uma nota } \\
\text { musical. }\end{array}$ & $\begin{array}{l}\text { Cada nota musical do piano é representada } \\
\text { pela sequência numérica de } 1 \text { a } 8 \text { do teclado } \\
\text { do computador. }\end{array}$ \\
\hline $\begin{array}{l}\text { O diálogo também terá um } \\
\text { acompanhamento sonoro mediante } \\
\text { áudios narrados. }\end{array}$ & $\begin{array}{l}\mathrm{Na} \text { segunda fase, o usuário } \\
\text { utilizará as teclas numéricas para } \\
\text { representar a sequência ditada na } \\
\text { etapa anterior. }\end{array}$ & $\begin{array}{l}\text { Ao clicar nos números que constam no } \\
\text { teclado numérico, o computador emitirá o } \\
\text { som de uma nota musical. }\end{array}$ \\
\hline $\begin{array}{l}\text { Para a passagem ou retorno aos } \\
\text { diálogos será necessário o } \\
\text { acionamento de uma seta para } \\
\text { direita. }\end{array}$ & $\begin{array}{l}\text { O sistema emitirá um tipo de } \\
\text { sinal sonoro quando o usuário } \\
\text { acertar e outro tipo de sinal } \\
\text { sonoro quando o usuário errar. }\end{array}$ & $\begin{array}{l}\text { O módulo possui } 3 \text { ícones representados } \\
\text { pelas imagens de um sapo, um balão junino } \\
\text { e uma estrela. }\end{array}$ \\
\hline $\begin{array}{l}\text { Ao final das instruções, o usuário } \\
\text { deverá clicar com o mouse no } \\
\text { ícone jogar ou voltar ao menu } \\
\text { inicial. }\end{array}$ & $\begin{array}{l}\text { Quando o usuário errar, ele } \\
\text { voltará para o início do jogo e } \\
\text { quando o usuário acertar, este } \\
\text { passará para a fase seguinte. }\end{array}$ & $\begin{array}{l}\text { Ao clicar nesses ícones, aparecerá a cifra } \\
\text { melódica, representada por números das } \\
\text { canções: "O sapo não lava o pé"; "Cai, cai } \\
\text { balão" e "Brilha, brilha estrelinha". }\end{array}$ \\
\hline
\end{tabular}

Fonte: Autores (2021).

Além dos requisitos específicos, há elementos comuns a todos os módulos que serão detalhados a seguir:

- Ícone casa: Ao clicar com o mouse sobre o ícone caracterizado pelo símbolo de uma casa, o usuário conseguirá retornar para a tela inicial do jogo.

- Ícone seta: Ao clicar com o mouse sobre o ícone caracterizado pelo símbolo de uma seta, as ações do módulo voltarão à versão inicial do módulo. 
O termo técnico para essas características dispostas na interface e que revelam ao usuário os procedimentos que eles podem fazer com cada elemento de forma perceptível denomina-se affordance. De acordo com Barbosa \& Silva (2010), o temo é um conjunto de características dos objetos de interface que mostram aos seus usuários como tais objetos podem ser manipulados.

No módulo "tocar" aparece a sugestão de três canções para que a criança possa experimentar o uso do piano digital. É relevante salientar que a escolha do repertório das canções descritas acima teve dois motivos: primeiro o piano digital possui apenas uma oitava, e segundo por serem canções conhecidas pelos alunos. Ago (2011) acredita que é apropriado trabalhar com canções que sejam do conhecimento das crianças, todavia não é recomendável limitar-se a elas.

\subsection{Design: interface e interação}

Para prototipação do recurso digital, etapa seis do método design thinking, foram concebidas versões interativas utilizando o Scratch. Este recurso, disponível na web, possibilitou que a equipe compartilhasse de forma remota as versões que iam sendo desenvolvidas e melhoradas ao longo do semestre. Vale ressaltar que, o desenvolvimento do protótipo circulou várias vezes entre o designer, a versão interativa e a avaliação, possibilitando o melhoramento da ferramenta e a revisão das soluções. Esse processo de criação do produto, que envolveu um movimento circular, possibilitou o refinamento do protótipo antes da entrega do produto, conforme foi exemplificado acima, na seção relacionada a IHC.

No que tange ao design do protótipo, o Melôkids apresenta uma interface inicial lúdica conforme a Figura 5, contendo a presença de dois personagens (feminino e masculino), caracterizados pela diversidade racial; a ilustração de um piano com uma oitava identificada pelas notas musicais, além de três botões para acessar os módulos do programa. A interface autoral sofreu modificações ao longo do processo e foi desenvolvida por componentes da equipe, os quais usaram o programa Photoshop.

As demais telas seguem a padronização da interface inicial, utilizando elementos de multimídias, como sons, imagens e textos a fim de proporcionar a interação acessível do usuário com o sistema. Vale ressaltar que as notas musicais inseridas no protótipo foram produzidas por um dos integrantes da equipe, formado em música, por meio do programa "Sonic Pi”. Quando a primeira interface for iniciada, o aluno poderá selecionar qual módulo desejará acessar, acionando um dos botões presente na barra do piano.

Figura 5. Interfaces do Melôkids.

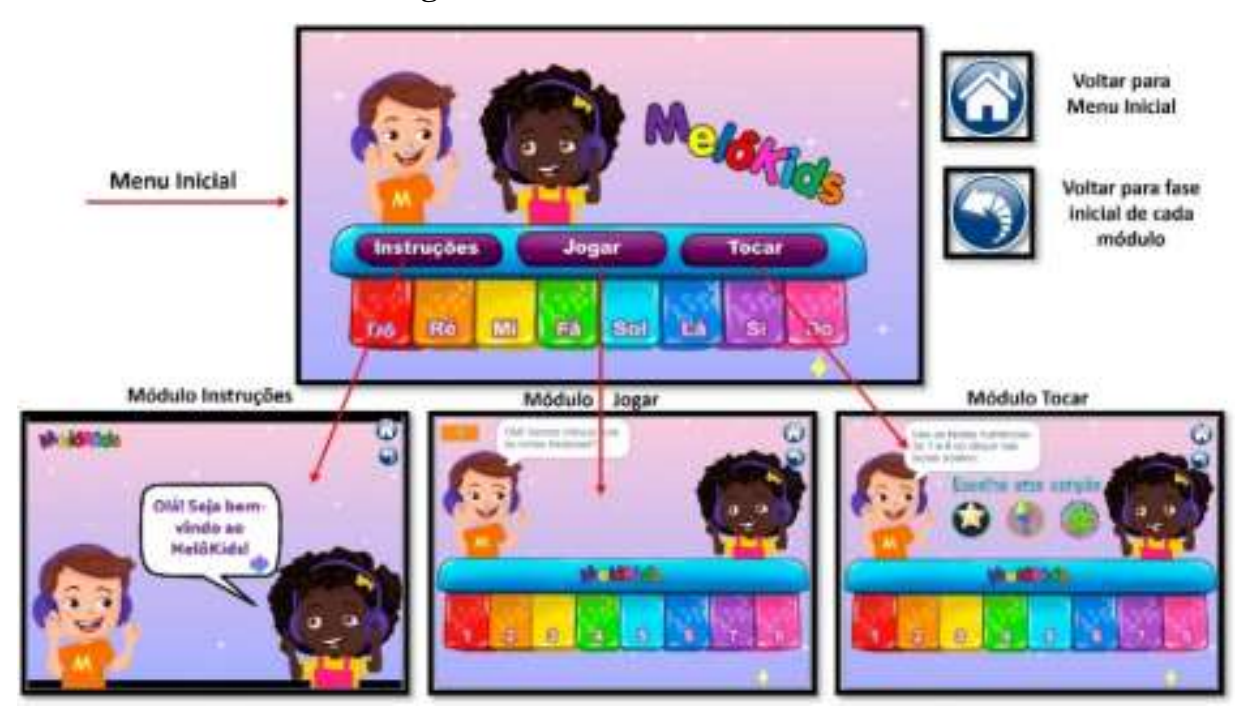

Fonte: Autores (2021). 
Ao acessar a interface do módulo "instruções”, o aluno interagirá com o sistema mediante um diálogo entre os personagens. O módulo possui uma linguagem visual e sonora, permitindo a acessibilidade. Já no módulo "jogar”, a interface segue o mesmo padrão das linguagens visual e sonora do módulo anterior. Nele, o recurso digital proporciona interação do aluno integrando o software com o hardware (teclas numéricas de computador). E, por fim, entrando no módulo "tocar", o personagem se comunica com o usuário por meio de um balão de fala. A interface também induz o aluno a escolher uma canção diante das imagens presentes nos ícones. As canções são representadas por cifras numéricas, uma forma de registro musical não convencional, sendo um dos requisitos detalhados pelas habilidades da BNCC. O protótipo pode ser acessado mediante o link (https://scratch.mit.edu/projects/563872977/).

\subsection{Avaliação}

A etapa da avaliação é de grande relevância porque verifica a usabilidade e a adequação do que foi proposto nos requisitos do protótipo. Ao ser executada, ela apresentará as falhas e inconformidades, tanto na implementação quanto na especificação. Essa validação é essencial para perceber se o recurso terá boa aceitação pelo público-alvo. Assim, o protótipo utilizou-se de três técnicas de avaliação: a Avaliação dos professores da disciplina, a Avaliação heurística de acordo com algumas heurísticas de Nielsen e um Teste com os usuários finais, que são os alunos dos anos iniciais do Ensino Fundamental.

Vale ressaltar que, essa seção apresenta as últimas etapas do método design thinking, no que se refere a implementação e a busca de contribuições dos especialistas e usuários finais. Conforme Coutinho et al. (2016) a obtenção do feedback do cliente é uma forma de possibilitar aprendizagem aos projetistas e perceber se a solução atendeu as metas.

\subsubsection{Avaliação dos professores da disciplina do mestrado}

Para a disciplina, foram solicitadas três entregas: o protótipo I, II e final. As entregas aconteceram remotamente mediante apresentações na plataforma SOLAR. Os professores, que são especialistas em Engenharia de Software, assistiram as apresentações das esquipes e apontaram limitações e sugestões. De acordo com essa proposta, a construção do Melôkids seguiu as seguintes entregas: o protótipo I para a conceção do menu inicial e do módulo "tocar"; o protótipo 2 para o desenvolvimento do módulo "instruções” e, por último, para a concepção do protótipo final a criação do módulo "jogar" e a integração dos outros módulos.

$\mathrm{Na}$ apresentação do protótipo I, relacionado à apresentação do menu inicial e do módulo "tocar", os professores identificaram os seguintes problemas quanto à usabilidade: 1) Os botões do menu inicial poderiam ter um destaque visual em 3D; 2) A representação das melodias das canções deveria apresentar destaques ao ser manipulada pelos usuários e 3) as teclas do piano poderiam ter um efeito visual. Todavia, de modo geral, os docentes elogiaram a proposta do design do protótipo e acharam adequada para o público, visto que possui uma interface lúdica e envolvente para os usuários finais. Essa análise foi valiosa e possibilitou o refinamento do produto.

No que tange à apresentação do protótipo II, relacionado à apresentação do "módulo instrução", os professores identificaram o seguinte problema com relação à usabilidade: os ícones "menu inicial" e "retornar para o início da fase" deveriam ter a função de mouse-over. O mouse-over é uma ação que permite o usuário ao passar o mouse sobre os símbolos mostrar o que eles significam. Para tal ação, os professores indicaram o script disponível no site: https://en.scratchwiki.info/wiki/Mouse-Over.

Por fim, na apresentação do protótipo final, foram apresentados os módulos jogar e a integração de todos os módulos. Nessa exposição os professores não relataram problemas e elogiaram o resultado do produto. 


\subsubsection{Avaliação heurística}

Para este método de avaliação, foram selecionadas algumas heurísticas básicas de Nielsen (1994) para encontrar os problemas ligados à usabilidade do Melôkids, tais como: 1) a visibilidade do estado do sistema; 2) o controle e a liberdade do usuário; 3) a consistência e a padronização; 4) o reconhecimento ao invés de memorização e 5) a flexibilidade e a eficiência de uso. No entendimento de Barbosa \& Silva (2010), Nielsen caracterizou como heurística um conjunto de condutas de usabilidade que descrevem as características desejáveis de interação e interface.

Para esse método de avaliação, os avaliadores colocam-se no lugar de um usuário final. Para Barbosa \& Silva (2010), os avaliadores precisam possuir conhecimento e experiência em atividades desenvolvidas no sistema interativo e tentar identificar problemas que os usuários podem vir a ter quando interagirem. Portanto, para a avaliação do Melôkids contou-se com o envolvimento de sete professores pedagogos, tendo em vista que, nos anos iniciais do ensino fundamental, hegemonicamente, atuam docentes habilitados em cursos de pedagogia cuja incumbência é lidar com todas as áreas do conhecimento escolar, inclusive música. Ademais, houve a participação de 2 professores de música.

A avaliação foi realizada por meio de um questionário on-line semiestruturado construído no Google Formulários, contemplando os aspectos éticos, dados sobre os avaliadores referentes ao conteúdo e a sua relação com as tecnologias e a escala de severidade dos problemas encontrados e sugeridos por Nielsen (1994), conforme detalhados na Tabela 1.

Tabela 1: Escala de severidade dos Problemas Encontrados.

\begin{tabular}{|c|c|c|}
\hline Severidade & Tipo de problema & Descrição \\
\hline 0 & Nenhum problema encontrado & Nada afeta a operação da interface \\
\hline 1 & Cosmético & Não há necessidade imediata de correção \\
\hline 2 & Simples & Problema de baixa prioridade (pode ser corrigido) \\
\hline 3 & Grave & Problema de alta prioridade (pode ser corrigido) \\
\hline 4 & Catastrófico & Muito grave (deve ser corrigido de qualquer forma) \\
\hline
\end{tabular}

Fonte: Dados adaptados de Nielsen (1994).

Devido ao contexto da pandemia da Covid-19, sendo impossível o contato físico com os avaliadores, o link do protótipo e o questionário foram enviados via WhatsApp para cada avaliador.

Dos nove especialistas envolvidos na avaliação, dois deles foram do sexo masculino e sete do sexo feminino, com idade superior a 30 anos. Todos consideraram ter uma boa experiência com as tecnologias, contudo, com relação ao conhecimento musical, as informações foram variadas: cinco com poucos conhecimentos; três afirmaram possuir conhecimentos; e um informou conhecer bastante. Quando questionados se já haviam utilizado recursos digitais em suas aulas de música, o resultado foi de 50\% para sim e 50\% para não. Os recursos usados e exemplificados por eles foram: o software Tam Tam Mini nos laptops Xo; jogos de dança e karaokê, YouTube, vídeos e aplicativos.

Após a avaliação dos especialistas, foram encontrados sete problemas concernentes aos três módulos, com uma escala de severidade que variou entre 1 e 3 , contendo erros pertencentes à heurística 5 , que trata da flexibilidade e eficiência de uso conforme a Tabela 2. 
Tabela 2: Problemas identificados pelos especialistas.

\begin{tabular}{|c|c|c|c|}
\hline Problemas identificados pelos especialistas & Módulo & $\begin{array}{l}\text { Heurística } \\
\text { relacionada }\end{array}$ & $\begin{array}{c}\text { Grau de } \\
\text { severidade }\end{array}$ \\
\hline "Demorando a passagem da setinha." & Instruções & 5 & 3 \\
\hline "As vozes do menino e da menina são as mesmas." & Instruções & 5 & 1 \\
\hline "Não permite acessar com o uso do mouse." & Jogar & 5 & 2 \\
\hline $\begin{array}{l}\text { "Enquanto as teclas musicais estão tocando para reproduzirmos, } \\
\text { seria interessante que o teclado do jogo estivesse bloqueado, sendo } \\
\text { liberado apenas quando a menina falasse que poderíamos JOGAR." }\end{array}$ & Jogar & 5 & 2 \\
\hline "Os balões com as notinhas precisam demorar mais um pouco." & Tocar & 5 & 1 \\
\hline $\begin{array}{l}\text { "Tem que diminuir o tempo de aparição do balão com os números } \\
\text { das notas musicais para se tocar a música escolhida." }\end{array}$ & Tocar & 5 & 3 \\
\hline $\begin{array}{l}\text { "As notas musicais poderiam durar mais tempo disponíveis na tela, } \\
\text { pois assim o jogador poderia treinar as músicas com mais calma e } \\
\text { exatidão." }\end{array}$ & Tocar & 5 & 2 \\
\hline
\end{tabular}

Fonte: Autores (2021).

Não foi identificado nenhum problema referente ao menu inicial. Alguns avaliadores deixaram elogios para o protótipo avaliado, destacando o colorido e a acessibilidade da plataforma, conforme as exemplificações nas falas abaixo:

- $\quad$ Especialista 1: "Excelente plataforma de interação. Bem colorido, chamativo e de linguagem acessível. Pode-se pensar também na possibilidade em outras línguas e ampliar a rede de interação com outros países. Pode-se pensar na possibilidade de se ter um metrônomo como indicativo de tempo e ajudar o público interagir e perceber que qualquer música tem um andamento, preenchido com sons e silêncio. Parabéns pela plataforma!”

- Especialista 2: "O protótipo está muito bonito, interessante e convidativo para as crianças; é uma ferramenta excelente para compor uma aprendizagem significativa acerca do ensino de música nas escolas.”

\subsubsection{Avaliação com os usuários finais - Alunos dos anos iniciais}

Para os ensaios de interação do recurso digital, foram envolvidos 12 estudantes do $3^{\circ}$ ao $5^{\circ}$ ano de uma escola pública de Ensino Fundamental do município de Maracanaú-Ceará. Esses alunos fazem parte de uma ação pedagógica da escola, denominada de "Projeto Música e Tecnologia na Escola", na qual se reúnem toda segunda-feira, via Google Meet, para o aprendizado da linguagem musical mediada por tecnologias.

Nenhum dos estudantes que participaram da experiência conhecia ou havia utilizado o protótipo até a sua aplicação. Dos participantes, três alunos são do $3^{\circ}$ ano, dois estudantes do $4^{\circ}$ ano e sete alunos são do $5^{\circ}$ ano. No que diz respeito ao sexo, sete estudantes são do sexo feminino e cinco estudantes são do sexo masculino. O experimento aconteceu no dia da aula do projeto, via Google Meet, um ambiente virtual já conhecido pelos alunos. Como nem todos os estudantes possuíam computador, uma aluna realizou o teste compartilhando a tela, enquanto os outros opinavam pelo chat da plataforma virtual.

Algumas instruções foram repassadas aos estudantes, dentre elas: a liberdade para participar da testagem; a avaliação quanto à usabilidade (se fácil ou difícil de utilizar); a avaliação da interface (se intuitiva ou atrativa) e a experiência com o recurso digital (sugestões, como o que mais gostou etc.).

A sessão da testagem durou uma hora, possibilitando a interação de todos os presentes com a colega e a professora. Ainda é relevante considerar que, após o encerramento da aula, o link foi disponibilizado no grupo de WhatsApp do projeto para que todos pudessem testar. Os estudantes que possuíam apenas celulares poderiam testar somente o módulo "instruções" e 
o módulo "tocar". O módulo "jogar" encontrava-se em desenvolvimento, não podendo ser testado em aparelhos Android no momento da avaliação, apenas quem possuísse computadores e notebooks.

Após o envio do link pelo WhatsApp, a professora solicitou aos alunos que testassem o recurso escolhendo uma das três canções disponíveis e gravassem um vídeo por meio do gravador de tela e enviassem ao grupo, caso fosse possível. A maior dificuldade encontrada, ao realizar o teste com os alunos, foi o fato de a maioria só possuir o celular como ferramenta tecnológica, ficando a testagem limitada. No entanto, o fato de ser um link facilitou bastante, pois a maioria dos equipamentos deles não havia memória suficiente para baixar aplicativos. Ademais, um dos problemas identificado por um deles, no momento da aula síncrona, ao questionar sobre o que significavam as imagens do sapo, do balão e da estrela contidas no módulo "tocar", foi que, para ele, as imagens emitiam sons, quando, na verdade, ao clicar aparecem as cifras melódicas de canções.

Por meio dos vídeos enviados pelos estudantes, percebeu-se que as tablaturas melódicas ainda precisavam de ajustes quanto ao tempo e ao tamanho, conforme já havia sido indicado nas etapas avaliadas anteriormente, uma vez que algumas crianças apresentaram um esforço visual ao tocar as canções.

Após a utilização do recurso, a professora questionou o que eles mais tinham gostado no protótipo Melôkids, e as respostas foram: "Eu gostei porque tem tudo colorido"; "Gostei de tudo"; "De tocar no melôkids"; "Tocar as músicas"; "Gostei muito de tocar no melôkids"; "Da música do balão"; "Gostei do jogo".

Em suma, a avaliação do protótipo nos três métodos foi de extrema relevância, os problemas relatados tanto pelos professores, como especialistas e usuários finais, já foram em sua maioria corrigidos. Como o objetivo inicial da equipe era apenas atender os requisitos da disciplina, os objetivos foram alcançados, contudo, almeja-se em uma outra fase o melhoramento do protótipo com o intuito de torná-lo um produto definitivo para o mercado.

\section{Considerações Finais}

Neste trabalho, foram expostas as estratégias utilizadas no ensino remoto para o desenvolvimento de um recurso digital voltado para a Educação Musical, o Melôkids, no contexto de uma disciplina de mestrado. Portanto, nesse âmbito, destacam-se vários procedimentos, tais como: a interdisciplinaridade dos conteúdos que envolveram o desenvolvimento do protótipo musical; a integração da metodologia utilizada pelos professores da disciplina do mestrado (método design thinking) com a metodologia disposta pela equipe (uso dos aspectos de IHC para o melhoramento da ferramenta); a utilização da linguagem Scratch para programação de recursos digitais; as plataformas e os recursos digitais encontrados para a adequação das atividades no formato remoto (Google Meet, SOLAR, WhatsApp, Trello e Sebrae Canvas); e avaliação do protótipo a partir de três métodos identificando os problemas para o melhoramento da ferramenta.

Em suma, ao ser feito um balanço geral, verificou-se que as estratégias utilizadas de forma remota pelos professores e membros da equipe possibilitaram a construção de um sistema interativo lúdico, divertido, contemplando conteúdos e habilidades musicais. As avaliações realizadas foram de extrema relevância, tendo em vista que apontaram os problemas no protótipo concernentes à flexibilidade e à eficiência de uso e uma necessidade de adequação da ferramenta aos diferentes contextos de uso e em tecnologias dessemelhantes.

Como o Melôkids encontra-se em fase de desenvolvimento no momento da escrita deste artigo, todas os problemas identificados estão sendo revistos e corrigidos. Todavia, vale ressaltar que a proposta inicial da sua construção foi atender aos requisitos impostos pela disciplina.

Ademais, o desenvolvimento do protótipo foi totalmente de autoria dos integrantes da equipe, desde o design até a sua programação interativa. Ressalta-se que nenhum membro tem formação na área da Computação, sendo esta, a principal 
Research, Society and Development, v. 10, n. 16, e116101623263, 2021 (CC BY 4.0) | ISSN 2525-3409 | DOI: http://dx.doi.org/10.33448/rsd-v10i16.23263

limitação da equipe. Contudo, os conhecimentos dos membros em programas de design, música e dos conceitos de programação possibilitaram a superação dos limites e ampliaram os conhecimentos com a integração e envolvimento de todos.

Há recursos digitais semelhantes na área, mas este se diferencia, pois além de ser específico para o uso em sala de aula, integra um jogo com um instrumento virtual, utilizando canções brasileiras com registros musicais não convencionais por meio das teclas numéricas de 1 a 8, conforme dispõe a BNCC. Entretanto, a maior contribuição deste trabalho está na variedade de estratégias utilizadas no ensino remoto para a construção do Melôkids, superando as limitações impostas pela pandemia da Covid-19.

Como trabalhos futuros, pretende-se implementar um sistema mais sofisticado para a apresentação das canções, incluir mais músicas no módulo "Tocar" e fazer a portabilidade do projeto para Android e para o formato HTML.

\section{Referências}

Ago, R. D. (2011). Musicando: um Software para Educação Musical nas séries iniciais. (Trabalho de Conclusão de Curso do curso de Engenharia de Software.) Universidade Federal de Porto Alegre. Porto Alegre, Rio grande do Sul, Brasil.

Barbosa, S. D. J \& Silva, B. S da. (2010). Interação humano-computador, Rio de Janeiro: Elsevier editora.il. - (Série SBC, Sociedade Brasileira de Computação)

Base Nacional Comum Curricular (2017). Ministério da Educação, Brasília. http://basenacionalcomum.mec.gov.br/images/BNCC_20dez_site.pdf.

Parâmetros Curriculares Nacionais para o Ensino Fundamental (1997). Ministério da Educação, Brasília. http://portal.mec.gov.br/seb/arquivos/pdf/arte.pdf.

Cota, D. M. (2016). Aplicativos musicais: uma reflexão sobre a inovação da educação musical. (Dissertação do Mestrado em Música pela Universidade Federal do Estado do Rio de Janeiro), Rio de Janeiro, Brasil. http://www.repositorio-bc.unirio.br:8080/xmlui/handle/unirio/11040

Coutinho, E. F, Gomes, G. A. M \& Antônio José, M. L. A (2016, abril). Applying design thinking in disciplines of systems development, $8^{a}$ Conferência Euro-Americana sobre Telemática e Sistemas de Informação (EATIS), pp. 1-8, DOI: 10.1109 / EATIS.2016.7520123. https://ieeexplore.ieee.org/document/7520123/metrics\#metrics

Cheng, L. \& Leong, S. (2017). "Educational Affordances and Learning Design in Music Software Development". Technology, Pedagogy and Education 26, n' 4, p. 395-407. doi: https://doi.org/10.1080/1475939X.2016.1267037

David, P. B., Green, J. L. \& Santos, V. E. C. (2020, novembro). Contextos de Aprendizagem para Interações Contingentes em Fóruns de Discussão Online: uma Investigação à Luz da Etnografia Interacional. In: Simpósio Brasileiro de Informática Na Educação, 31., p. 332-3412020. Porto Alegre, Rio Grande do Sul, Brasil. doi: https://doi.org/10.5753/cbie.sbie.2020.332.

Jesus, E. A., Uriarte, M. Z. \& Raabe, A. L. A. (2010). Zorelha: Um Objeto de Aprendizagem Para Auxiliar o Desenvolvimento da Percepção Musical em Crianças de 4 a 6 Anos. Revista Brasileira de Informática na Educação, [S.1.], v. 18, n. 01, p. 91, jul. 2010. ISSN 2317-6121. doi: http://dx.doi.org/10.5753/rbie.2010.18.01.91.

Franco, M. A. S. (2005). Pedagogia da Pesquisa-Ação. Educação e Pesquisa, São Paulo, v. 31, n. 3, p. 483-502.

Gordon, E. (2000). Teoria de Aprendizagem Musical, Competências, conteúdos e padrões. Lisboa: Fundação Calouste Gulbenkian.

Meireles, M. C. \& Bonifácio, B. (2015, outubro). Uso de Métodos Ágeis e Aprendizagem Baseada em Problema no Ensino de Engenharia de Software: Um Relato de Experiência. Brazilian Symposium on Computers in Education. Simpósio Brasileiro de Informática na Educação - SBIE, [S.1.], p. 180. ISSN 23166533. doi: http://dx.doi.org/10.5753/cbie.sbie.2015.180.

Nielsen, J. \& Molich, R. (1990). “Heuristic evaluation of user interfaces”. Proceedings of ACM CHI'90, pp. 249-256.

Nielsen J. (1994). “Heuristic Evaluation”. In: R. Mack \& J. Nielsen (eds.), Usability Inspection Methods. New York, NY: John Wiley \& Sons, pp. 25-62.

Pereira, E., Costa, R., \& Souza, R. (2021). Elaboração e Avaliação do Aplicativo Educacional: Jogo de Memória Musical. Tecnia, 6(1), 154-176. http://revistas.ifg.edu.br/tecnia/article/view/920

Rocha, C. C. \& David, P. B. (2020). Avaliação da Arquitetura da Informação em Portais de Periódicos: Uma Discussão Teórica. Perspectivas em Gestão \& amp; Conhecimento, [S. l.], v. 10, n. 2, p. 223-243, 2020. https://periodicos.ufpb.br/index.php/pgc/article/view/50239.

Rodrigues, A. (2020). Ensino remoto na Educação Superior: desafios e conquistas em tempos de pandemia. SBC Horizontes. ISSN 2175-9235. Recuperado de http://horizontes.sbc.org.br/index.php/2020/06/17/ensino-remoto-na-educacao-superior/.

Scratch. (2021). Imagine, program, share. https://scratch.mit.edu/.

Sebrae. (2021). Crie modelos de negócios com o Sebrae Canvas. https://sebraecanvas.com/\#/?checkedSAS=true.

Sharp, H., Rogers, Y. \& Preece, J. (2007). Interaction design: beyond human-computer interaction, $2^{\mathrm{a}}$ edição. New York, NY: John Wiley \& Sons, 2007. 
Research, Society and Development, v. 10, n. 16, e116101623263, 2021

(CC BY 4.0) | ISSN 2525-3409 | DOI: http://dx.doi.org/10.33448/rsd-v10i16.23263

Silva, A. C., Silva, J. C. A. \& Penteado, R. A. D., Silva, S. R. P. (2004). Aplicabilidade de Padrões de Engenharia de Software e de IHC no Desenvolvimento de Sistemas Interativos, In: IV Congresso Brasileiro de Computação - $\quad$ CBComp, p. $118-123$. http://www.niee.ufrgs.br/eventos/CBCOMP/2004/html/pdf/Engenharia_Software/t170100152_3.pdf

Sobreira, E. S. R., Takinami, O. K. \& Dos Santos, V. G. (2013, dezembro). Programando, Criando e Inovando com o Scratch: em busca da formação do cidadão do século XXI. Jornada de Atualização em Informática na Educação, [S.1.]. ISSN $23167734 . \quad<$ https://www.brie.org/pub/index.php/pie/article/view/2592>. Acesso em: 13 nov. 2021.

Trello. Atlassian Copyright. (2021). Disponível em: https://trello.com/pt-BR/home.

Yue T., Briand L.C. \& Labiche Y. (2009). A Use Case Modeling Approach to Facilitate the Transition towards Analysis Models: Concepts and Empirical Evaluation. In: Schürr A., Selic B. (eds) Model Driven Engineering Languages and Systems. MODELS. Lecture Notes in Computer Science, volume 5795. Springer, Berlin, Heidelberg. doi: https://doi.org/10.1007/978-3-642-04425-0_37

Winckler, M. A. A. \& Nemetz, F.; Lima, J. V. de. (2000). Interação entre aprendiz e computador: métodos para desenvolvimento e avaliação de interfaces. In: Tarouco, Liane (Org.). Tecnologia Digital na Educação. PGIE/UFRGS, Porto Alegre, Brasil. p.7-33. 